IOS Press

\title{
Introduction
}

\section{Translational Research and Drug Discovery for Neurodegeneration: Challenges for Latin America}

\author{
K.S. Jagannatha Rao ${ }^{\mathrm{a}, 1, *}$, Gabrielle B. Britton ${ }^{\mathrm{a}, 1, *}$, Luisa Lilia Rocha Arrieta ${ }^{\mathrm{b}}$, \\ Norberto Garcia-Cairasco ${ }^{\mathrm{c}}$, Alberto Lazarowskid ${ }^{\mathrm{d}}$, Adrián Palacios ${ }^{\mathrm{e}}$, \\ Antoni Camins Espuny ${ }^{\mathrm{f}}$ and Ricardo B. Maccioni ${ }^{\mathrm{g}}$ \\ ${ }^{a}$ Centro de Neurociencia, Instituto de Investigaciones Científicas y Servicios de Alta Tecnología, AIP (INDI- \\ CASAT AIP), Panamá and Sistema Nacional de Investigación (SNI), SENACYT, Panamá \\ ${ }^{\mathrm{b}}$ Depto. Farmacobiología del Centro de Investigación y de Estudios Avanzados del Instituto Politécnico Nacional, \\ México \\ ${ }^{\mathrm{c}}$ Full Professor of Physiology (Neurophysiology), Director of the Neurophysiology and Experimental Neuroethol- \\ ogy Laboratory (LNNE), Physiology Department - Ribeirão Preto School of Medicine, University of São Paulo, \\ Ribeirão Preto, SP, Brasil \\ ${ }^{\mathrm{d}}$ Instituto de Fidiopatologia y Bioquímica Clínica (INFIBIOC), Facultad de Farrmacia y Biouimican (FFyB), \\ Universidad de Buenos Aires (UBA), Buenos Aires, Argentina \\ ${ }^{\mathrm{e}}$ Centro Interdisciplinario de Neurociencia de Valparaiso, Facultad de Ciencias, Universidad de Valparaiso, \\ Valparaiso, Chile \\ ${ }_{\mathrm{f}}^{\mathrm{f}}$ Department of Pharmacology, Toxicology and Therapeutic Chemistry, Faculty of Pharmacy and Food Sciences, \\ Barcelona, Spain \\ ${ }^{\mathrm{g}}$ Full Professor, Departamento de Neurología y Neurocirugía, University of Chile, Santiago, Chile
}

Pre-press 3 June 2021

Perhaps one of the most significant scientific challenges is to understand the human brain. Neuroscience research has had a considerable impact on individuals, families, and society. However, before we can have a real impact on public health, we need a greater understanding of biological processes that

\footnotetext{
${ }^{1}$ These authors contributed equally to this work.

*Correspondence to: K.S. Jagannatha Rao and Gabrielle B. Britton, Centro de Neurociencia, Instituto de Investigaciones Científicas y Servicios de Alta Tecnología, AIP (INDICASAT AIP), Panamá and Sistema Nacional de Investigación (SNI), SENACYT, Panamá. E-mail: jrao@indicasat.org.pa. (K.S. Jagannatha Rao), E-mail: gbritton@indicasat.org.pa. (Gabrielle B. Britton)
}

underlie the wide variety of neurological and psychiatric disorders such as Alzheimer's disease (AD), Parkinson's disease, schizophrenia, depression, traumatic brain injury, epilepsy, and many others.

It is a great challenge and responsibility of science to unravel the brain's secrets through translational research and drug discovery in order to improve the lives of individuals with these devastating conditions. In the past decade, outstanding discoveries have been made that have made possible novel and multidisciplinary approaches to understanding the brain's mysteries. We are witnessing the practical benefits of the human genome project and of novel 
technologies for probing neuronal connections, and have made noteworthy advances in imaging technologies and nanoscience. These discoveries emerged in response to the need for cross border collaborations among all fields of science as the only way to make progress in translational neuroscience. A notable example is the National Institutes of Health (NIH) Brain Research through Advancing Innovative Neurotechnologies (BRAIN) Initiative, a \$500 million investment intended to better understand brain structure and function with a focus on developing novel therapies for neurological and psychiatric disorders.

There is ample evidence of the contributions that Latin America has contributed to neuroscience research. Still, across countries, there is also a need for more funding, mainly to attract talent, prevent "brain drain," and improve infrastructure, each of which is essential to facilitating regional networks, interdisciplinary groups, and overall productivity in terms of publications and patents. It is time to consolidate a consortium for neuroscience research in Latin America, which should include as many countries as possible and actively support scientifically less productive countries under the premise that knowledge has no boundaries [1].

Recently, a team of neuroscientists from various Latin American countries came together to consolidate the recent advances in brain research in "Translational Research and Drug Discovery for Neurodegeneration: Challenges for Latin America," a special issue of the Journal of Alzheimer's Disease. The idea to organize this special issue resulted from the First Seedings Neuroscience Workshop carried out at the Instituto de Investigaciones Científicas y Servicios de Alta Tecnología, AIP (INDICASAT AIP) in Panama and supported by the Latin America Regional Committee of the International Brain Research Organization (IBRO). Dr. Jagannatha Rao KS and Dr. Gabrielle B. Britton of INDICASAT AIP in collaboration with Luisa Lilia Rocha Arrieta (Center for Research and Advanced Studies. Mexico), Norberto Garcia Cairasco (University of São Paulo, Brasil), Alberto Lazarowski (Universidad de Buenos Aires, Argentina), Adrián Palacios (Universidad de Valparaíso, Chile), Antonio Camins Espuny (University of Barcelona, Spain), and Ricardo B. Maccioni (Universidad de Chile, Santiago) collaborated in order to highlight the progress that neuroscience researchers have made across countries and regions. We thank Dr. George Perry, Editor-in-Chief, and Beth Kumar, Managing Editor, of the Journal of
Alzheimer's Disease for making this issue possible. The publications represent a sample of notable investigations from the following countries: Mexico, Columbia, Venezuela, Republic Dominican, Chile, Argentina, Panama, Spain, USA, and New Zealand, all of which currently are making high impact collaborative contributions to the field of neuroscience.

The topics covered include biomarkers in aging and age-related diseases, novel molecules as neuroprotectants, cohort studies of cognition in Hispanic populations, novel proteins and pathways in neurodegeneration, as well as computational neuroscience and alternative animal models for the study of neurodegenerative pathways. Taken together, these studies bring us closer to revealing novel drug targets and therapeutics, and represent significant contributions of neuroscience from Latin America.

Araya et al. [2] describe synaptic changes in retinal neurons that occur during neurodegeneration in an AD mouse model, which include an early phase of physiological hyperactivity and a later stage of hypoactivity. These observations are linked to concomitant changes in glutamate and GABA that affect the excitatory and inhibitory balance of retinal circuits. Martinez-García et al. [3] also describe alterations in piriform cortical excitability that may contribute to olfactory dysfunction in AD.

Mercerón-Martínez et al. [4] review recent animal models of AD, particularly the mechanisms of synaptic plasticity, and present various therapeutic alternatives developed in their laboratories that may be ready to test in AD. Guzman-Martinez et al. [5] also emphasize integrated "multitarget" approaches that combine various preventive factors that may lead to better control of the disease. Hüttenrauch et al. [6] review the literature on yogic interventions as complements to therapies in early pre-clinical stages of $\mathrm{AD}$. Ettcheto et al. [7] discuss therapeutic strategies based on the maintenance of dendritic spines and synapses aimed at improving the cognitive deterioration that occurs in AD. The administration of trophic factors such as brain derived neurotrophic factor may play a fundamental role among other associated strategies such as physical exercise, the use of anti-inflammatory drugs, and avoiding obesity.

Merelli et al. [8] review the primary role of hypoxia in the development of inflammation and oxidative stress and discuss the potential for recombinant human erythropoietin in pharmacological doses administered via the route nasal to act as an antiinflammatory and antioxidant anti-apoptotic agent. We are sorry to mention that our beloved colleague 
Dr. Amalia Merelli died on October 13, 2020 as a result of a breast cancer metastasis while preparing the review.

Various reviews and results of studies provide novel insights into molecular pathways that may potentially serve as therapeutic targets. Busquets et al. [9] review the importance of the C. Jun-N-terminal kinases (JNK) isoforms in the control of events that lead to the development of $\mathrm{AD}$, and suggest that the specific inhibition of JNK isoforms in neuron subpopulations may represent an appropriate strategy for the treatment of AD. Posada-Duque and Cardona-Gómez [10] focus on cyclin-dependent kinase 5 (CDK5) and its role in the integrity of the neurovascular unit in $\mathrm{AD}$ and cognitive impairment. Leyton et al. [11] report data implicating DEF8, a gene involved in the autophagy pathway, in the pathophysiology of AD. Lastly, using a computational approach, Chaparro et al. [12] present several candidates that may serve to prevent the redox reactions mediated by redox metal cations.

The contribution of Cuervo-Zanatta et al. [13] supports an important interaction between periphery organs and the central nervous system. Their results indicate how cognitive impairment is associated with alterations of gut microbiota. Santiago-Castañeda et al. [14] present evidence indicating that propylparaben can be used to avoid the consequences of traumatic brain injury. Their work is an effort for repurposing an old drug (propylparaben) with a novel effect. Flores-Cuadra et al. [15] discuss a cost-effective approach compatible with developing countries, namely, the use of non-transgenic mouse models and their potential to inform the molecular biology and therapeutic strategies for combatting AD.

Several studies make a notable contribution to the current literature gaps about dementia and related risk factors in Hispanics living in developing countries. The extensive work of Gil et al. [16] and Castro et al. [17] highlights the relationship between neuropsychiatric symptoms and cognitive impairment and dementia, including biomarkers of depressive symptoms, in population-based studies of older Hispanics in Maracaibo City, Venezuela. Castillo-Mendieta et al. [18] report the potential of plasma biomarkers of neuropathological signs of $\mathrm{AD}$ as a cost-effective approach to identifying individuals at risk for $\mathrm{AD}$ in a sample of Mexican AD patients. Arévalo et al. [19] propose a role for vitamin D receptor polymorphisms in MCI and AD in a Chilean sample and include studies in peripheral blood mononuclear cells. Ayala-Gross et al. [20] report the results of cross-sectional analyses that suggest that chronic dysregulation of cortisol secretion may contribute to cognitive impairment using data from PAHO/WHO agencies. From Panama, Oviedo et al. [21] report the association between APOE4 expression and dysfunction in specific cognitive domains in participants from the Panama Aging Research Initiative cohort, an ongoing prospective cohort study that began in 2011. Cognitive and genetic testing infrastructure, as well as biomarker studies of individuals with $\mathrm{AD}$ and MCI in this cohort, have begun to reveal the relevant risk factors for older adults in Panama, and lay the groundwork for back translation studies.

Orjuela et al. [22] and Lakey-Beitia et al. [23] each have reported significant advances in our understanding of natural products in preventing or reverting the amyloid beta aggregation process that has been a focus of AD research. Naturally occurring products are a potential source of molecules that may be able to inhibit $A \beta_{42}$ peptide aggregation and related processes, including metal dyshomeostasis, which may indirectly cause aggregation. Both of these studies take important steps toward a better understanding of AD neuropathologies through leveraging of international collaborations. Likewise, Soto-Mercado et al. [24] evaluate the effect of a synthetic cannabinoid in a natural model of $\mathrm{AD}$ and provide evidence that a combination of cannabinoids and other compounds may be potential treatments for familial AD.

This special issue provides an overview of novel contributions in neuroscience from Latin America and the Caribbean and serves as a starting point for further collaborations. The importance of coordinated actions within a regional action plan is supported by Ibanez et al. [25] within the framework of the Latin America and the Caribbean Consortium on Dementia (LAC-CD). Such initiatives are essential to advancing dementia-related clinical and research activities in the region.

We thank all the authors for their support despite the hardships created by COVID 19. We especially thank anonymous reviewers for their timely reviews.

KSR and GBB are thankful to SNI, SENACYT (Panama) for the support. The publication of this special was financed by INDICASAT AIP, Panama.

\section{REFERENCES}

[1] Forero DA, Trujillo ML, González-Giraldo Y, Barreto GE (2020) Scientific productivity in neurosciences in Latin America: A scientometrics perspective. Int J Neurosci 130, 398-406. 
[2] Araya-Arriagada J, Bello F, Shivashankar G, Neira D, Durán-Aniotz C, Acosta ML, Escobar MJ, Hetz C, Chacón M, Palacios AG (2021) Retinal ganglion cells functional changes in a mouse model of Alzheimer's disease are linked with neurotransmitter alterations. J Alzheimers Dis 82, S5S18.

[3] Martínez-García I, Hernández-Soto R, Villasana-Salazar B, Ordaz B, Peña-Ortega F (2021) Alterations in piriform and bulbar activity/excitability/coupling upon amyloid- $\beta$ administration in vivo related to olfactory dysfunction. $J$ Alzheimers Dis 82, S19-S35.

[4] Mercerón-Martínez D, Ibaceta-González C, Salazar C, Almaguer-Melian W, Bergado-Rosado JA, Palacios AG (2021) Alzheimer's disease, neural plasticity, and functional recovery. J Alzheimers Dis 82, S37-S50.

[5] Guzman-Martinez L, Calfío C, Farias GA, Vilches C, Prieto R, Maccioni RB (2021) New frontiers in the prevention, diagnosis, and treatment of Alzheimer's disease. $J$ Alzheimers Dis 82, S51-S63.

[6] Hüttenrauch M, Lopez-Noguerola JS, Castro-Obregón S (2021) Connecting mind-body therapy-mediated effects to pathological features of Alzheimer's disease. J Alzheimers Dis 82, S65-S90.

[7] Ettcheto M, Busquets O, Cano A, Sánchez-Lopez E, Manzine PR, Espinosa-Jimenez T, Verdaguer E, Sureda FX, Olloquequi J, Castro-Torres RD, Auladell C, Folch J, Casadesús G, Camins A (2021) Pharmacological strategies to improve dendritic spines in Alzheimer's disease. $J$ Alzheimers Dis 82, S91-S107.

[8] Merelli A, Repetto M, Lazarowski A, Auzmendi J (2021) Hypoxia, oxidative stress, and inflammation: Three faces of neurodegenerative diseases. J Alzheimers Dis 82, S109-S126.

[9] Busquets O, Parcerisas A, Verdaguer E, Ettcheto M, Camins A, Beas-Zarate C, Castro-Torres RD, Auladell C (2021) c-Jun N-terminal kinases in Alzheimer's disease: A possible target for the modulation of the earliest alterations. $J$ Alzheimers Dis 82, S127-S139.

[10] Posada-Duque RA, Cardona-Gómez GP (2021) CDK5 targeting as a therapy for recovering neurovascular unit integrity in Alzheimer's disease. J Alzheimers Dis 82, S141-S161.

[11] Leyton E, Matus D, Espinoza S, Benitez JM, Cortes BI, Gomez W, Arévalo NB, Murgas P, Manque P, Woehlbier U, Duran-Aniotz C, Hetz C, Behrens MI, SanMartín CD, Nassif M (2021) DEF8 and autophagy-associated genes are altered in mild cognitive impairment, probable Alzheimer's disease patients, and a transgenic model of the disease. $J$ Alzheimers Dis 82, S163-S178.

[12] Chaparro D, Flores-Gaspar A, Alí-Torres J (2021) Computational design of copper ligands with controlled metal chelating, pharmacokinetics, and redox properties for Alzheimer's disease. J Alzheimers Dis 82, S179-S193.

[13] Cuervo-Zanatta D, Garcia-Mena J, Perez-Cruz C (2021) Gut microbiota alterations and cognitive impairment are sexually dissociated in a transgenic mice model of Alzheimer's disease. J Alzheimers Dis 82, S195-S214.

[14] Santiago-Castañeda C, Segovia-Oropeza M, Concha L, Orozco-Suárez SA, Rocha L (2021) Propylparaben reduces the long-term consequences in hippocampus induced by traumatic brain injury in rats: Its implications as therapeutic strategy to prevent neurodegenerative diseases. JAlzheimers Dis 82, S215-S226.

[15] Flores-Cuadra JA, Madrid A, Fernández PL, Pérez-Lao AR Oviedo DC, Britton GB, Carreira MB (2021) Critical review of the Alzheimer's disease non-transgenic models: Can they contribute to disease treatment? J Alzheimers Dis $\mathbf{8 2}$, S227-S250.

[16] Gil M, Alliey-Rodriguez N, Lopez-Alvarenga JC, Diego V, Gaona CA, Mata L, Pirela RV, Chavez CA, de Erausquin GA, Melgarejo JD, Maestre GE (2021) Neuropsychiatric symptoms among Hispanics: Results of the Maracaibo Aging Study. J Alzheimers Dis 82, S251-S261.

[17] Castro F, Melgarejo JD, Chavez CA, de Erausquin GA Terwilliger JD, Lee JH, Maestre GE (2021) Total plasma homocysteine and depressive symptoms in older Hispanics. J Alzheimers Dis 82, S263-S269.

[18] Castillo-Mendieta T, Arana-Lechuga Y, Campos-Peña V, Sosa AL, Orozco-Suarez S, Pinto-Almazán R, Segura-Uribe J, Rodríguez-Sánchez de Tagle AJ, Ruiz-Sánchez E, GuerraAraiza C (2021) Plasma levels of amyloid- $\beta$ peptides and tau protein in Mexican patients with Alzheimer's disease. $J$ Alzheimers Dis 82, S271-S281.

[19] Arévalo NB, Castillo-Godoy DP, Espinoza-Fuenzalida I, Rogers NK, Farias G, Delgado C, Henriquez M, Herrera L, Behrens MI, SanMartín CD (2021) Association of vitamin D receptor polymorphisms with amyloid- $\beta$ transporters expression and risk of mild cognitive impairment in a Chilean cohort. J Alzheimers Dis 82, S283-S297.

[20] Ayala-Grosso C, Torrico F, Ledezma-Ruiz M, Busolo-Pons M (2021) Chronic stress in cognitive processes: Cortisol dynamic range of secretion is associated with perception of unsafety environment in a Venezuelan population. $J$ Alzheimers Dis 82, S299-S312.

[21] Oviedo DC, Perez-Lao AR, Flores-Cuadra JA, Villarreal AE, Carreira MB, Grajales SA, Britton GB (2021) Apolipoprotein $\varepsilon 4$ affects multiple domains of neuropsychological functioning in a sample of elderly Hispanics. $J$ Alzheimers Dis 82, S313-S319.

[22] Orjuela A, Lakey-Beitia J, Mojica-Flores R, Hegde ML, Lans I, Alí-Torres J, Rao KS (2021) Computational evaluation of interaction between curcumin derivatives and amyloid- $\beta$ monomers and fibrils: Relevance to Alzheimer's disease. J Alzheimers Dis 82, S321-S333.

[23] Lakey-Beitia J, Burillo AM, La Penna G, Hegde ML, Rao KS (2021) Polyphenols as potential metal chelation compounds against Alzheimer's disease. J Alzheimers Dis 82, S335-S357.

[24] Soto-Mercado V, Mendivil-Perez M, Jimenez-Del-Rio M, Velez-Pardo C (2021) Multi-target effects of the cannabinoid CP55940 on familial Alzheimer's disease PSEN1 E280A cholinergic-like neurons: Role of $\mathrm{CB}_{1}$ receptor. $J$ Alzheimers Dis 82, S359-S378.

[25] Ibanez A, Parra MA, Butler C; The Latin America and the Caribbean Consortium on Dementia (LAC-CD) (2021) The Latin America and the Caribbean Consortium on Dementia (LAC-CD): From networking to research to implementation science. J Alzheimers Dis 82, S379-S394. 